\title{
SPATIAL AND TEMPORAL ANALYSIS OF MASS MOVEMENT USING DENDROCHRONOLOGY
}

\author{
R.R. Braam, E.E.J. Weiss and P.A. Burrough, Utrecht
}

\section{SUMMARY}

Tree growth and inclination on sloping land is affected by mass movement. Suitable analysis of tree growth and tree form can therefore provide considerable information on mass movement activity.

This paper reports a new, automated method for studying the temporal and spatial aspects of mass movement activity. Ringwidth data from only a few cores per tree are required. The method uses filtering techniques and statistical time series analysis.

Preliminary results for two landslides in the Barcelonnette area of the French Alps show a relative stability of movement activity over the last hundred years (no trend) and short periodicity (six to seven year periods) of mass movement activity.

The advantages of the method (over other, mostly visual, methods) are its clearness, flexibility, repeatability and rapidity. However, further testing is needed to examine its reliability.

ISSN $0341-8162$

(C) 1987 by CATENA VERLAG,

D-3302 Cremlingen-Destedt, W. Germany

$0341-8162 / 87 / 5011851 /$ US\$ $2.00+0.25$

\section{INTRODUCTION}

Mass movements in forested, hilly or mountainous areas are of concern to all involved in watershed management. Major earth movement can cause loss of valuable resources, damage to roads and buildings and can threaten human safety. It is of considerable interest for strategic, longterm planning to know whether the frequency of mass movements in an area is increasing or is stable over time. Fortunately, data on the past history of mass movements are contained within the rings and form of trees growing on the slumped land. Suitable analysis of tree growth and tree form can therefore provide considerable information on the temporal and spatial aspects of mass movement in an area.

Tree growth and inclination on sloping land is affected by mass movement and erosion. Tree response to mass movement can be seen from the width, pattern and form of annual growth rings and from the form of the trunk and branches. ALESTALO (1971), introduced the term "dendrogeomorphology" for the study of geomorphic processes using data gathered from trees and gave a general account of the possibilities. SHRODER (1978), described the general effects of mass movements on trees and presented a method for analysing long-term mass 
movements using several different tree responses to tilting. He also reviewed recent literature in dendrogeomorphology (SHRODER 1980).

This paper reports a new, automated method for analysing the ringwidth data of trees on areas subject to mass movement. The spatial and temporal variability of mass movements can be analysed using only ring width data from a few cores per tree. The method presented here is based on those of ALESTALO (1971) and SHRODER (1978), but uses filtering methods and statistical time series analysis. Analysis is carried out with a computer program named CATIR which has been developed for this purpose. The method is illustrated using data from the Barcelonnette area of the Ubaye valley in the French Alps.

\section{MASS MOVEMENT, TILTING OF TREES AND ECCENTRIC RING GROWTH}

A geomorphological process, such as mass movement, can influence tree growth in different ways. Mass movement can cause events such as
a) inclination of tree trunk (tilting),
b) shear of root or stem wood,
c) burial of stem wood,
d) exposure of root wood,
e) corrasion (damage to the bark by rub- ble),
f) nudation (increase in water stress) or
g) inundation.

A tree may respond to these events in various ways, such as by
a) the termination,
b) suppression, or
c) increase of growth,
d) the growth of reaction wood (differ-

ent structure, morphology and colour of cells) and eccentric annual rings,

e) sprouting and

f) succession

(SHRODER 1978).

SHRODER (1978) introduced the term "Process- Event- Response- chain" for these kind of relationships. Most of the above mentioned tree-responses can be caused by more than one kind of event. For mass movement, the growth of reaction wood in the trunk, and the consequent eccentric ring growth, however, is caused only by inclination.

When a tree is tilted, the inclined trunk responds by curving upwards so that vertical growth is maintained (fig.1). The curvature is caused by the pressure (coniferous trees) or tension (deciduous trees) that develops alongside the trunk as a result of the growth of reaction wood on the lower side of the trunk of coniferous trees and on the upper side of the trunk of deciduous trees (WESTING 1965). By counting the number of eccentric rings of the inclined tree trunk, the eccentricity of the annual rings can be used to identify the year of tilting, and thus to date the mass movement activity (ALESTALO 1971). Multiple inclined trees can show very complex growth forms as a result of curvature, especially when the directions of tilt were different and periods between successive tilts were long (decades). Examination of the form of the trunk can reveal the minimum number of tilts, their directions and relative age (BRAAM 1985, BRAAM et al. 1987). Examination of the amount of eccentricity of successive annual rings of multiple inclined trees can reveal the dates of inclination, alhough this may be difficult if sampling of cores is not based on analysis of the form of the trunk.

Tilting of trees can have causes other 

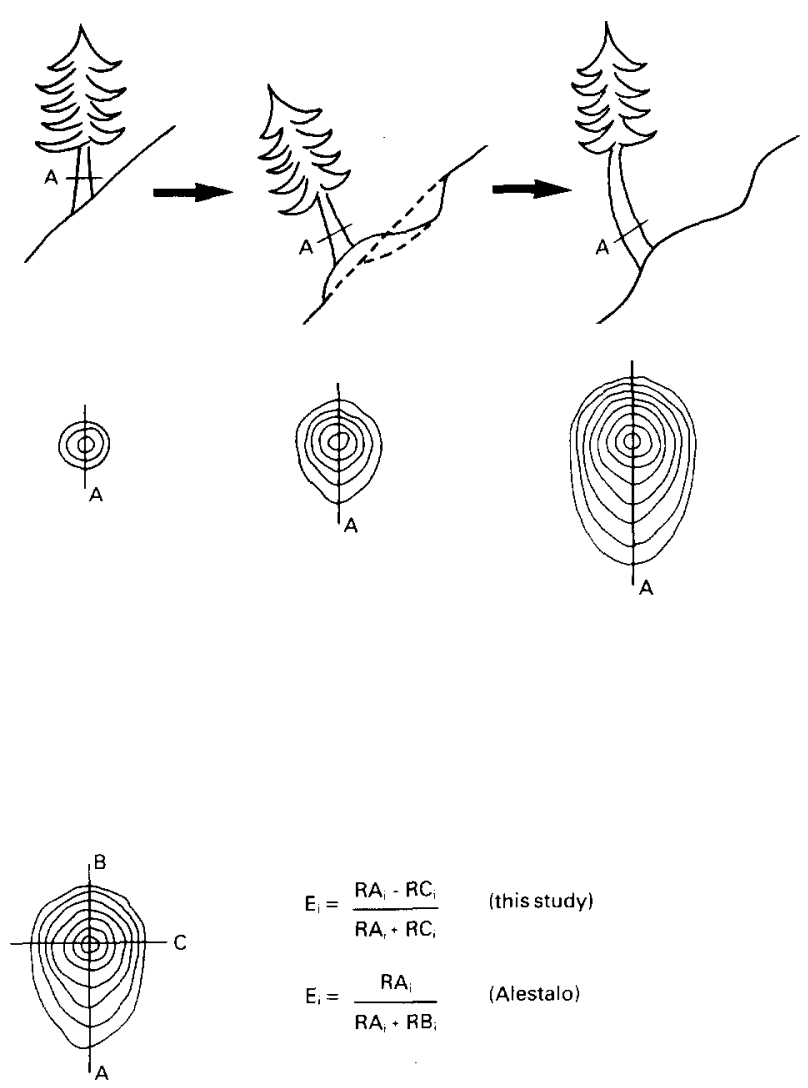

$$
\begin{aligned}
& E_{i}=\frac{R A_{i}-R C_{i}}{R A_{i}+R C_{i}} \quad \text { (this study) } \\
& E_{i}=\frac{R A_{i}}{R A_{i}+R B_{i}} \quad \text { (Alestalo) }
\end{aligned}
$$

Fig. 1: Above:

Mass movement induced tilting of a coniferous tree and consequent eccentric growth of annual rings and curvature of trunk. Below: Two methods of computing the eccentricity of annual rings for each year $\left(E_{i}\right)$ from ringwidths measured along different radii $(R A, R B, R C)$. than mass movement, such as wind throw, but mass movement-induced tilting can easily be identified from the local situation in most cases. Eccentricity of annual rings can also be caused by uneven distribution of moisture, nutrient supply or growth substances, as a result of an unequally developed crown and/or rootsystem, but in these cases it is not accompanied by reactionwood (recognizable from its different colour and morphology).

The eccentricity of annual rings can be measured in a simple way from crosssections of the stem or from, at least two, radii at right angles to each other as shown in fig. 1 .

The eccentricity can be modelled as a function of inclination and the form of the crown and root system, the latter two treated as one complex factor.

$$
E_{i}=a+b I_{i}+c C R_{i}+e
$$

where

$E_{i}=$ eccentricity in year i

$I_{i}=$ inclination in year $\mathrm{i}$

$C R_{i}=$ crown-root term for year $\mathrm{i}$

$a, b, c=$ constants, and

$e \quad=$ error term.

Several authors (ALESTALO 1971, SHRODER 1978) have tried to establish the quantitative relationship between the angle of inclination and the amount of eccentricity. Although a small change in the angle of inclination has a clear influence on the amount of eccentricity, 
an absolute relationship cannot be established. This is probably the result of not taking into account the influence of the crown-root factor, but it is also possible that sensitivity for inclination differs among tree species or even between individual trees. Further, it seems that in the case of undisturbed trees, with a straight and upright trunk and evenly developed crown and root system, the amount of eccentricity fluctuates considerably from year to year (BRAAM 1985). However, these uncertainties are of no great importance in analysing the course of eccentricity over the lifetime of a tree because:

1. we are not interested in year to year fluctuation, which can be regarded as noise, but in sudden changes of the level of eccentricity with a duration longer than a few years,

2. we are not interested in absolute changes but in relative changes, the significance of which can be statistically tested and

3. we can ignore the crown-root factor as long as this is constant or relatively small.

Assuming the third point, formula (1) can be written as:

$E_{i}=a+b I_{i}+e$

Now we can date tilting by measuring the significance, at a specified level, of relative changes in the level (or local mean) of the eccentricity of annual rings of inclined trunks.

The dates of tilting can be regarded as estimated dates of mass movement activity. The activity of mass movement in an area over a period can be analysed by applying the concept of a ProcessEvent-Response-Index as presented by SHRODER (1978). This index is calculated by the number of trees with an inclination response dated for year $i$, weighted on the total number of sampled trees alive in year $i$ and is given as a percentage. Calculation of the index for each year provides an index series of mass movement activity for the area.

More mass movememnt activity, as measured with this index, means thus more inclined trees. The distribution of trees and of mass movement activity over the area has an important influence on the index value. In case of uniform distribution of trees over the area, the index measures the relative number of places where movements occurred and not the relative number of occasions when movement took place.

The use of annual rings can produce a lag in dating of one year when tilting occurs after the growing season but before the end of the calender year, as eccentric growth will not start before the next growth season.

\section{METHODS}

\subsection{CORE SAMPLING AND MEASUREMENT OF ECCENTRICITY}

Although eccentricity is best measured with cross sections of the trunk, in most cases this is not permitted or desirable. However, a few cores are often enough to establish the relative changes of the level of eccentricity during the lifetime of a tree when sampling is guided by tree form. Cores should be taken along radii in the direction of inclination and at right angles to it. Additional cores will be needed in case of multiple inclination directions in order to avoid dating problems as explained in the accompanying technical note (BRAAM et al. 1987).

Tree rings are sampled using a stain- 
less steel incremental bore of $5 \mathrm{~mm}$ diameter and $300 \mathrm{~mm}$ long. The cores are extracted and the ring widths counted using a microscope and a pulse generator (2500 pulses for $1 \mathrm{~cm}$ horiontal displacement). Data are stored on disc using an Apple lle personal computer. Subsequent time series analysis was performed on the Cyber 180-855 of the Academic Computer Centre Utrecht.

Eccentricity is measured as illustrated in fig. 1 and computed according to:

$$
E_{i}=\left(R A_{i}-R C_{i}\right) /\left(R A_{i}+R C_{i}\right) * 100 \%(3)
$$

where

$E_{i}=$ eccentricity in year $\mathrm{i}$ and

$R A=$ ringwidth along radius $\mathrm{A}$

$R C=$ ringwidth along radius $\mathrm{C}$

The measurement of eccentricity is thus essentially the same as ALESTALO's (1971) method, where ring width on the lower part of the trunk is given as a percentage of total diameter growth. The reason for a somewhat different approach is that ring width on the higher side of inclined trunks is severely suppressed, which inflates measurement error and increases the chance of (partially) missing rings. This alternative method leads to smaller values of eccentricity for the same annual ring than ALESTALO's method, but as we are interested in significant changes of the relative level of eccentricity this is not a problem.

A time series of eccentricity is established by computing the value of eccentricity for all annual rings and placing them in the correct year (see FRITTS 1976 for a good account of tree ring synchronisation). A computer program for automated synchronisation of tree ring data has been developed.

\subsection{ANALYSIS OF ECCENTRICITY SERIES}

The aim is to establish a series of inclination occurences through analysis of a time series of estimated eccentricity. An inclination occurrence is defined as a significant change of the relative eccentricity level with a duration of several years. For a linear, regularly sampled series the location of absolute changes in the value of an attribute can be estimated using a filtering technique known as "Split Moving Window", or "SMW" (WEBSTER \& WONG 1968). This technique, combined with a Student's t-test for differences between sample means is much suited for analysis of eccentricity level changes (fig.2). A double window (of equal length) with a distance of one or more years (an uneven number should be chosen if the values are to be related to the original years) is moved along the series. For each position the difference of window (= sample) means is tested, at a specified significance level, against the null hypothesis of no difference (difference caused by random variations). The test is two-tailed as both increased and decreased levels of eccentricity are important. The degrees of freedom are equal to 2(n-1), being the number of years in a window, but when the window variances are suspected to differ one should take (n-1) instead (SNEDECOR 1966). The calculated value of $t$ for each year of the eccentricity series (except for the years on the edges can be compared with the critical value at the chosen significance level. A value of $t$ equal or larger than the critical value dates a significant change in the level of eccentricity and therefore indicates tilting and thus mass movement activity. When several successive years show a t-value larger 


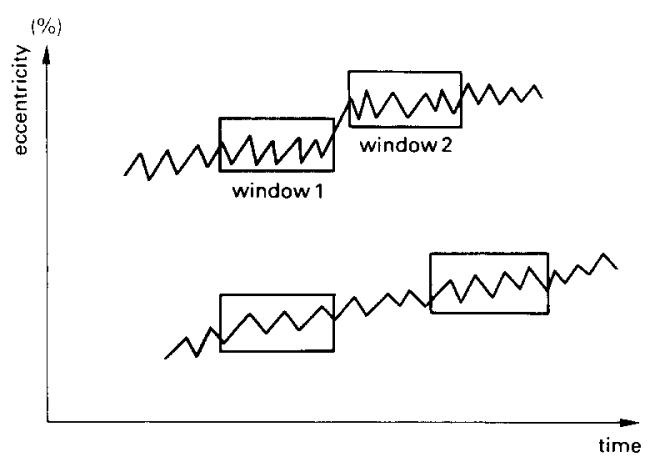

$\mathrm{t}=\frac{\overline{\mathrm{E}}_{1}-\overrightarrow{\mathrm{E}}_{2}}{\mathrm{~S}_{\mathrm{pm}}}$; where,

$\overline{\mathrm{E}}=$ window mean ( $\mathrm{n}$ years per window).

$S_{p m}=\sqrt{\frac{2 S^{2}}{n}} \quad$ and

$S^{2}=\frac{\sum\left(E_{1}-\bar{E}_{1}\right)^{2}+\sum\left(E_{2}-\bar{E}_{2}\right)^{2}}{2(n-1)}$

than the critical value, the most likely year of tilting is that with the highest $\mathrm{t}$-value. However, as gradual tilting can occur, it seems reasonable to count every year with an above critical t-value as an indication of tilting. When tilting is gradual, the two halves of the split moving window can be separated by one or more sampling intervals (fig.2). The use of this "mullion" in the window increases the sensitivity of the technique when change is gradual. However, it should be noted that gradual decrease of eccentricity can be the result of trunk curvature.

A time series of tilting occurrences is reached by assigning a "one" to each year with a t-value above the chosen significance level and a "zero" for every other year of the series. Each year with a tilting occurrence indicates mass movement, possibly with a lag of one year when tilting occurred after the growth season. Fig. 3 gives an example of this
Fig. 2: Measurement of significant changes of the level of eccentricity with the Split-Moving- Window ( $S M W$ ) technique combined with calculation of a student's t-test on difference between sample (window) means. sort of analysis for a tree (Larix decidua) from the study area near Barcelonnette in the French Alps.

\subsection{ANALYSIS OF SPATIAL AND TEMPORAL VARIABILITY OF MASS MOVEMENT ACTIVITY}

The series of tilting occurrences of a number of sampled trees from an area can be used to analyze the spatial and temporal variability of mass movement activity in the area. A shift of activity downslope for example can be followed by sampling trees on a transect, or from subareas. Temporal variations in activity of the whole area can be measured by calculating an index number for each year (SHRODER 1978) :

$I_{i}=\left(\sum_{k=1}^{n} R(k)_{i}\right) /\left(\sum_{k=1}^{n} A(k)_{i}\right) * 100 \%$ 

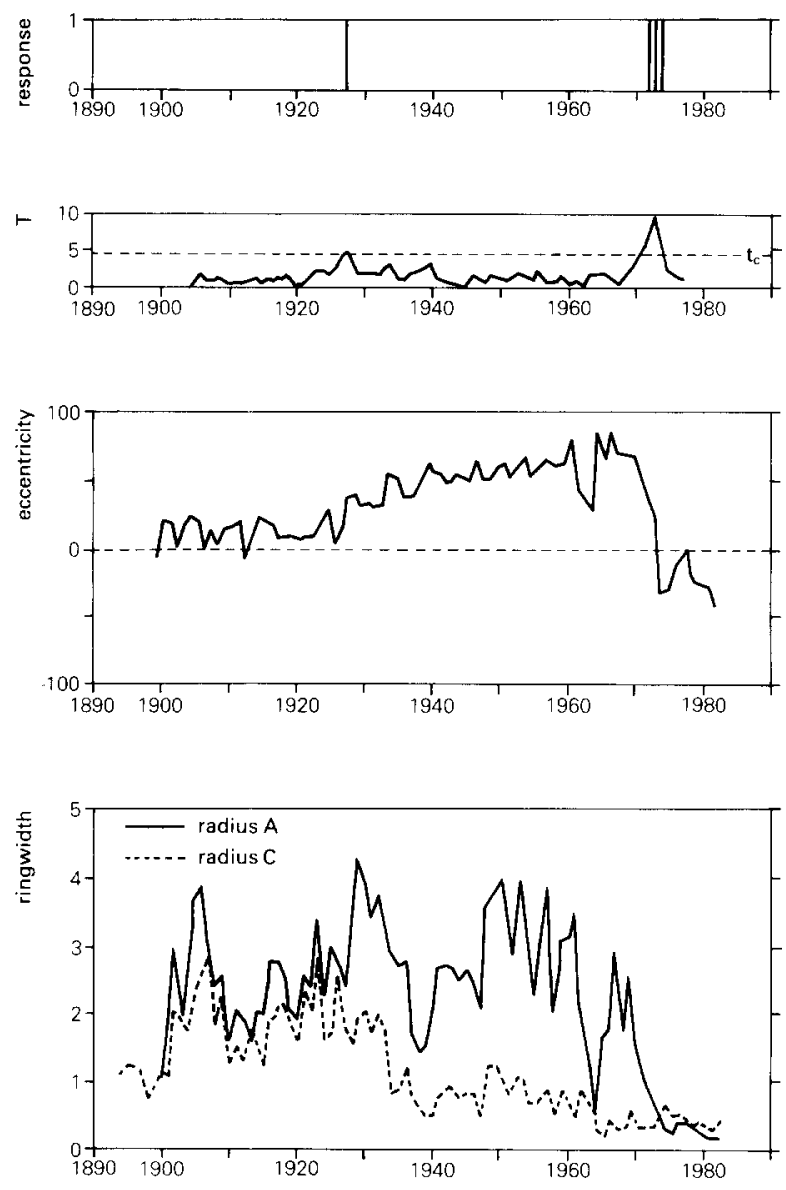

Fig. 3: Dating of tilting occurrances with SMV and t-test for a Larix decidua on a landslide near Barcelonnette in the French Alps. Significance level is $0.01(99 \%$ confidence). where

$I_{i} \quad=$ index of activity for year $\mathrm{i}$,

$R(k)_{i}=$ trees tilted in year $\mathrm{i}$, and

$A(k)_{i}=$ sampled trees alive in year $\mathrm{i}$, and

$n \quad=$ total number of sampled trees.

The index relates the number of inclined trees to the total number of sampled trees for each year. What it reveals about mass movement activity depends on the distribution of sampled trees and movement activity over the area. Movements as small as the patch of ground containing the roots of a single tree (often observed in the study area) are the smallest measurable mass movements with this method.

The activity index series achieved in this way can be analysed for the presence of trends, periodicity and serial correlation. It can be used to relate mass movement to possible causal factors such as precipitation. This can be done with normal techniques of time series analysis such as time plots, curve fitting, autocorrelation, cross correlation and spectral analysis. For an account of these techniques, see for example CHATFIELD (1984) or DAVIS (1986). 


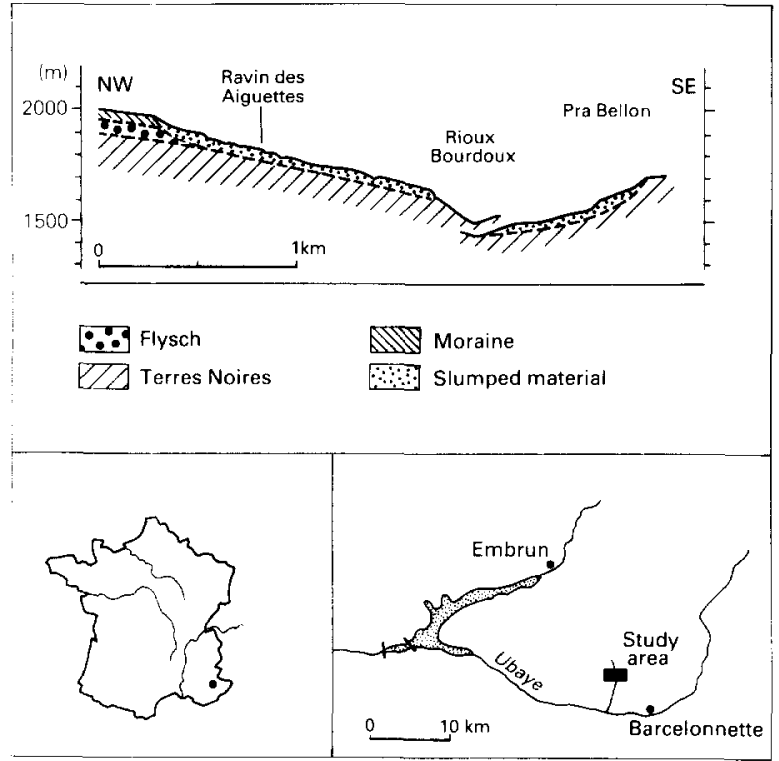

Fig. 4: Location and geological profile of the study area.

\section{AN EXAMPLE: THE RIOUX BOURDOUX VALLEY}

The Rioux Bourdoux Valley, a tributary to the Ubaye, situated about $4 \mathrm{~km}$ northwest of Barcelonnette (fig.4) is well known for the great mass movement activity and frequency of mudflows in the past centuries. Activity in this area dates at least from the 15 th century as a result of almost complete deforestation in the Middle ages. Bedrock in this area consists of highly erodable jurassic clayey black marls known as "Terres Noires" on the lower parts of the slopes and chalky Flysch (Eocene Nappe with dark marls at its base) on the higher parts. Also the relatively high annual precipitation in the valley which is estimated to be of the order of $1500 \mathrm{~mm}$, i.e. almost twice that of the Barcelonnette station values, (ANONYMOUS 1976) contributes to the high erosion rate in the area. From the end of the last century until 1977 stream correction works have been carried out in order to stabilize the river profile of the Rioux Bourdoux. Besides drainage works and the placing of numerous small dams in the catchment area and larger ones in the main channel this compromised reforestation of the largest part of the area. Although the frequency of mudflows rapidly decreased, they were not stopped completely and mass movements are still active (as can be seen from the numerous recently tilted trees in the area).

\section{MASS MOVEMENT ACTIVITY}

In order to study the course of mass movement activity since reforestation, trees were sampled at two (pilot)locations in the valley. Fifty-four cores were taken from twenty-six pine-trees at the unstable upper part of the "Ravin des Aiguettes"-slide, which is situated be- 
tween $1500 \mathrm{~m}$ and $2000 \mathrm{~m}$ on the western valley slope, and seventy-two cores were taken from thirty pine-trees at a small secondary slide at the edge of the "Pra-Bellon"-slide, a large moving patch of Terres Noires situated on the eastern slope (fig.4). Of these, twenty trees were useful for analysis from Ravin des Aiguettes and twenty-one from Pra Bellon. The remainder could not be synchronized as a result of false and missing rings and core damage.

Eccentricity values were computed and analysed with the SMV-technique for different window sizes (2, 3, 4 and 5) and mullion size (1, 3 and 5 yrs) for several trees to compare the results. Larger window size and/or mullion results in more dates of inclinations, although very large window size reduces the number of dates. A window size of five years in combination with a one year mullion was considered to be optimal and was chosen to analyse all the trees, thus producing series of $t$-values for each tree. The largest peaks of $t$-values in the series indicate the most reliable dates of inclination of trees, and thus of mass movement activity. The choice of a specific significance level gives the critical value of $t$ and makes it possible to see which years are important and which are not. In this study a significant level of 0.01 was chosen. The critical value of $t$ at this level is 3.36 when sample variances are equal and 4.60 when unequal.

Process-Event-Response-Indexes were computed for both areas using $\mathrm{t}=3.36$ as well as $t=4.60$. The main difference between the results of using different t's is a shift of the index mean from $7 \%$ to $17 \%$ and an increase in variance of $40 \%$, the pattern however, remains the same (crosscorrelation at zero lag being 0.70 with $t=8.00$ ). Further analysis has been carried out using only the more reliable index series, computed with critical $\mathrm{t}=$ 4.60 .

The index series of both Ravin des Aiguettes and Pra Bellon show no visually clear trend (fig.5). The absence of trend is also clear from the low correlation coefficients at lags higher than zero (fig.6). This means that mass movement activity has been stable over the total measurement period and no clear influence of reforestation and maturing of wood is revealed. However, fluctuations seem to be present in both index series. Therefore, Fourier analysis was carried out to estimate the spectrum of the index series. The spectrum shows the amount of variance that is explained by periodic componens in the range of two (the Nyquist frequency) to $\mathrm{N}$ (total length of the series) years (CHATFIELD 1984). The contribution to the variance of the data by a specific periodic component is called the power. Periodic components with a wavelength of about 7 and 21 years are important in the power spectrum of the Pra Bellon index series and components at about 6 and 18 years in the spectrum of the Ravin des Aiguettes series (fig.7). Cross correlation of the two index series is low for all lags (fig.6), highest coefficient at a lag of $+13,14 \mathrm{yrs}$ ( $\mathrm{r}$ $=0.5$ ).

Fig. 5 compares the index series with annual precipitation data from Barcelonnette. There are no high correlation coefficients at any lag between the two series and precipitation (highest $r$ of 0.4 is at a lag of +11 years for Ravin des Aiguettes) all $r$ values are lower than 0.4 for Pra Bellon and not significant at 0.01 level. Also the precipitation data show no similar periodicity, as is clear from their spectrum (fig.7c). This seems to suggest that, although precipitation is an 

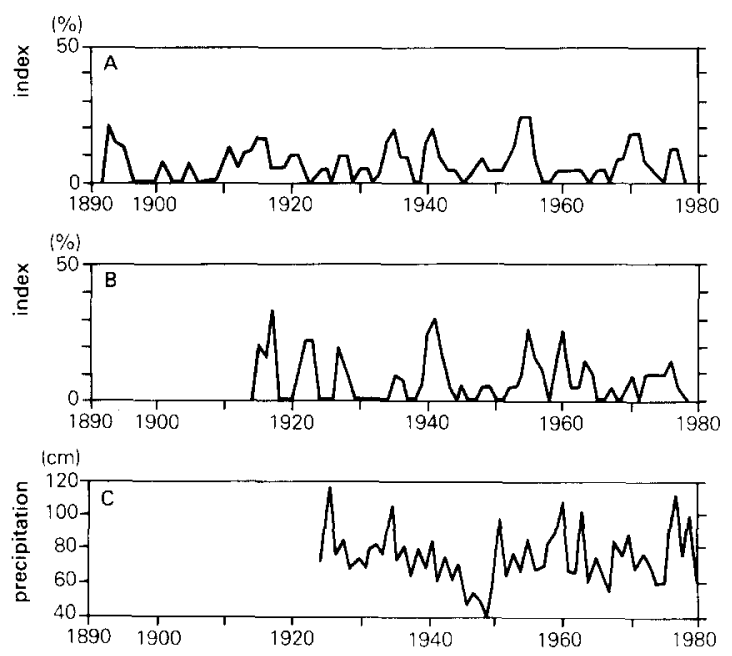

Fig. 5: Index series of mass movement activity for Pra Bellon ( $A$ ) and Ravin des Aiguettes ( $B$ ), and annual precipitation from 1925 to 1980 for the Barcelonnette station $(1135 \mathrm{~m})$.


Fig. 6: Correlograms showing autocorrelation coefficients at different lags for the index series of Pra Bellon ( $A$ ) and Ravin des Aiguettes (B) and cross correlation coefficients at different lags between them ( $C$ ).

Only the highest peaks $(r>0.3)$ are significant at the 0.01 level. 

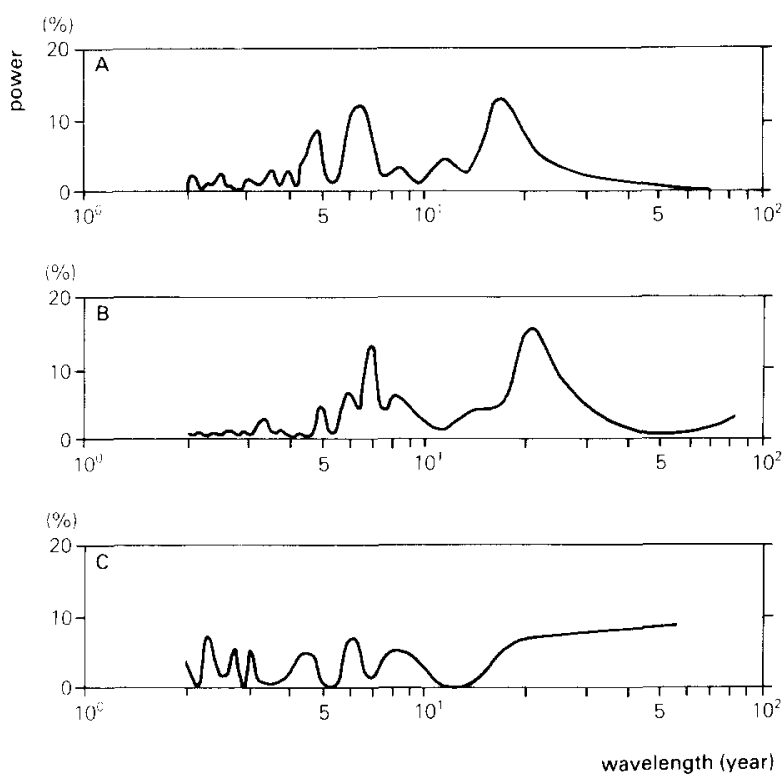

Fig. 7: Powerspectra, estimated by a Fourier representation, of the index series of Pra Bellon $(A)$ and Ravin des Aiguettes $(B)$ and of the annual precipitation series $(C)$ from the Barcelonnette station $(1135 \mathrm{~m})$. important factor in inducing mass movement by increasing the water content of the soil, it does not directly cause movement activity. Rather it seems that shear stress is gradually built up, reaching the critical value after some time, and then is suddenly decreased as a result of movement taking place, after which shear stress builds up again. The timescale of this periodicity will be caused by relatively constant factors as bedrock, mean annual precipitation and slope angle.

\section{CONCLUSIONS}

Although further testing of the suggested method is needed, it seems to offer good prospects, the main advantages being its clear use of evaluation criteria, its flexibility, repeatability and rapidity (compared with other, visual, methods of interpretating the tree ring data).

Results for the study area show an absence of trend in the index series of movement activity over the last hundred years. The influence of reforestation and maturing of the wood on mass movement activity is therefore not clear. Periodic components with wavelangths of six and eighteen years (Pra Bellon) and seven and twenty-one years (Ravin des Aiguettes) are important in the index series, as is clear from their spectra. The absence of trend and the presence of short term periodicity in mass movement activity indicate a transient equilibrium situation which might be the result of the stream correction works carried out in the area. However, this is not certain, as there are no data about mass movement activity before these correction works were made.

\section{ACKNOWLEDGEMENT}

The authors thank Henk Ploeger and the Laboratory of Physical Geography for their friendly help in using computer facilities and technical assistance. 


\section{REFERENCES}

ALESTALO, J. (1971): Dendrochronological interpretation of geomorphic processes. Soc. Geogr. Fenn., Fennia 105, 1-140.

ANONYMOLS (1976): Torrent du Rioux Bourdoux. Serie domaniale de Saint Pons (Basse Alps). Digne, 1966, updated 1976.

BRAAM, R.R. (1985): Dendrogeomorfologisch onderoek Barcelonnette (zuidfranse Alpen). Students paper. Geografisch Instituut Rijksuniversiteit Utrecht.

BRAAM, R.R., WEISS, E.E.T. \& BURROUGH, P.A. (1987): Dendrogeomorphological analysis of mass movement. A technical note on the research methods. CATENA 14, 585-589.

CHATFIELD, C. (1984): The analysis of time series, an introduction. Third edition. Chapman and Hall. London.

DAVIS, J.C. (1986): Statistical methods in Geology. Wiley. (2nd Edition).

FRITTS, H.C. (1976): Tree rings and Climate. Academic Press, London, New York.

SNEDECOR, G.W. (1966): Statistical Methods, IOWA Univ. Press.

SHRODER, J.F. (1978): Dendrogeomorphological analysis of mass movements on Table Cliffs Plateau Utah. Quaternary Research 9, 168-185.

SHRODER, J.F. (1980): Dendrogeomorphology, review and new techniques of tree-ring dating. Progress in Physical Geography 4, 161-188.

WEBSTER, R. \& WONG, I.F. (1968): A numerical procedure for testing soil boundaries interpreted from airphotographs. Photogrammetria 24, 1969, 59--72.

WESTING, A.H. (1965): Formation and function of compression wood in gymnosperms. Botanical Review 31, 381-480.

\footnotetext{
Address of authors:

R.R. Braam, E.E.J. Weiss and

P.A. Burrough

Department of Physical Geography, University of Utrecht

Utrecht, The Netherlands
} 